\title{
Editorial
}

\section{Lost in Numbers: The Art and Science of Medicine}

\author{
Rajeev Gupta \\ Editor, RUHS Journal of Health Sciences, Academic and Research Development Unit, \\ Rajasthan University of Health Sciences, Jaipur, Rajasthan, India
}

It has been famously said: A good surgeon knows how to operate; a better surgeon knows when to operate but the best surgeon knows when not to operate. ${ }^{1}$ In the same hyperbole we could narrate the mantra of good medical practice as: Every doctor knows what to prescribe (medical or surgical treatments), a good doctor knows when to prescribe but a great doctor knows when not to prescribe. All the medical teaching and learning should be directed to this mantra if we wish to create good and humane doctors in India well versed with both, the science and the art of medicine.

According to the World Health Organization (WHO), the ideal doctor population ratio should be 1 for 1,000 persons. According to the year 2018 National Health Profile report by the Ministry of Health, Government of India, the situation in India is critical. ${ }^{2}$ Accordingly to the report, there is one government allopathic doctor per 11,082 population, one government hospital bed per 1,844 population and one state-run hospital for every 55,591 population. The report also says that India has a little over 10 lakh allopathy doctors to treat its 1.3 billion people. This works out to a doctor to population ratio of $1: 11,082$ while the WHO prescribes a ratio of $1: 1,000$. The doctor density is far worse in the country's poorer states. For instance, in Bihar, there is one government allopathic doctor per 28,391 population, down from 2013, when there was one government allopathic doctor per 20,207 population. While the WHO norms do not specify if it should include government and non-government doctors, the former are used as benchmark to measure the availability of a doctor per 1,000 population. The ministry data is only for government doctors and if we include more than half of qualified medical doctors working in non-governmental sector in the country, the ratio would come down to about a half to 1 per 5500-6000 population.

The crisis is even starker in the dental sector, where despite a surge in dental surgeons, there is a striking imbalance in the average population being treated by them. As per the report, the number of government dental surgeons has increased by five times, from around 50,000 in 2003 to over 2.5 lakh in 2017.That works out to one government dental surgeon per $1,76,004$ population as against the WHO norms of 1:7,500. The report again does not count more than $60 \%$ dental surgeons working in the non-governmental sector. The data also points towards inadequate hospital infrastructure, and a huge disparity between urban and rural healthcare. In India, there are over 23,000 hospitals with around 7 lakh beds. Almost 20,000 hospitals are in the rural area with close to 3 lakh beds. Urban areas have fewer hospitals, around 3,700, but the majority of the beds totaling above 4.3 lakh. $^{2}$ Three issues are important and should be discussed against this background.

A singular focus on numbers as portrayed by this report ${ }^{3}$ and highlighted in media is unfortunate. A good example of failure of numbers is in comparison of healthcare costs and outcomes of Cuba with USA. Cuba has the same number of physicians per 1000 as USA, spends less than a tenth on health per person ( $\$ 650)$ as compared to USA $(\$ 9,400)$ but is better on most of the health parameters including life expectancy at birth. USA also spends more per capita on health care than any other country in the world but 39 countries have longer life expectancies. ${ }^{4}$ This is due to better patient management at primary care (Cuba, Scandinavian countries) and less wasteful expenses at tertiary care as happens in USA. A classical example of too many physicians prescribing more treatments and not knowing when to stop. ${ }^{5}$ Increasing the number of physicians in India without caring for the quality of the product is a knee-jerk reaction to WHO recommendations and shall result in greater utilization of health care, more wasteful investigations, more pharmacological and surgical interventions and would not improve outcomes. ${ }^{6}$ The latest iteration of National Medical Commission Bill, if fully implemented, is an innovative intervention with potential to improve quality of scientific knowledge in 
doctors passing out of medical colleges. ${ }^{7}$

The second issue relates to quality of teaching in various medical institutions. Gone are the days when medical education was held using guru-shishya interactions as knowledge translation technology. Emerging technologies have changed the teaching methods and eroded the teacher-pupil relationship. Instead, we have an internet-savvy student asking all the difficult questions about rare diseases. The teaching should focus not only on teaching with use of electronic technologies but also impart wisdom to differentiate useful from wasteful. This would prevent inappropriate prescription of investigations and treatments and could create good and great doctors.

The third issue relates to wastage in healthcare that may result from focus on numbers rather than quality of medical students and doctors. The much-needed universal health care program in India is about to be launched as National Health Protection Scheme (NHPS). ${ }^{3}$ The focus of this scheme should be primary care based health assurance rather than secondary and tertiary care based health insurance. This issue has been debated extensively and the latter strategy is advocated. ${ }^{8-10}$ Good quality primary care doctor with reasonable experience in management of common conditions and having intermediate level of experience should be appointed at these healthcare centers to improve outcomes.

It is, therefore, recommended that instead of just chasing numbers the medical bureaucrats should focus on improving quality of medical education by better teaching technologies and empowerment of medical students in science of medicine. This is envisaged in the new National Medical Commission Bill 2017. . Role models in healthcare should be promoted and revival of teacherstudent relationship to promote the art of medicine is urgently needed. It may be a good idea if out of hospital practice of medical teachers in stopped so that the faculty could devote more time to teaching and research. The rapidly changing profile of diseases in India and rising chronic disease burden make it urgent for state and central governments to collaborate with researchers and agencies that implement programs to improve health care to further the quality agenda in the healthcare system in India. ${ }^{11}$

\section{REFERENCES}

1. Simpson L. What makes a good surgeon? J Natl Med Assoc. 2008;100:261-64.

2. Chandna H. Just 1 doctor to treat 11,000 patients: the scary truth of India's government healthcare. ThePrint.in. 2018. Available at: https://theprint.in/governance/just-1doctor-to-treat-11000-patients-govt-report-detailsindias-health-crisis/74013/ . Accessed 24 June 2018.

3. Central Bureau of Health Intelligence. National Health Profile 2018. $13^{\text {th }}$ Issue. Available at: http://www. cbhidghs.nic.in/index 1.php?lang=1\&level=2\&sublinkid $=88 \&$ lid $=1138$. Accessed 24 June 2018 .

4. Rosling H. Factfulness: The reasons we're wrong aboutand why things are better than you think. London. Sceptre: Hodder\& Stoughton. London. 2018; 185-203.

5. Morone JA. How to think about "Medicare for All". N Engl J Med 2017; 377:2209-11.

6. Gupta R. Wastage in healthcare needs to be tackled as part of India's universal healthcare plan. BMJ 2017; 357:j2145.

7. National Medical Commission Bill 2017. Available at: http://164.100.47.5/newcommittee/press_release/bill/Co mmittee\%20on\%20Health\%20and\%20Family\%20Welf are/NMC\%20Bill.pdf. Accessed 24 June 2018.

8. Ghosh D. In Modicare the most ambitious healthcare mission yet? Available at: http://worldhealthpartners.org/ 2018/02/is-modicare-the-most-ambitious-healthcaremission/. Accessed 24 June 2018.

9. Ghosh S. Publicly financed health insurance schemes. Econ Pol Weekly 2018; 53(23):16-18.

10. Reddy KS. Health care reforms in India. JAMA 2018; EPub.doi:10.1001/jama.2018:5284.

11. Mohanan M, Hay K, Mor N. Quality of health care in India: challenges, priorities and the road ahead. Health Affairs 2016; 35:1753-58. 